\title{
Crônica e Charge: o Cotidiano e Suas Representações
}

\author{
Chronic and Charge: the Daily and its Representations
}

TOZATTI, Danielle de Marchi; Mestre; Universidade Estadual de Londrina - UEL

daniellemarchi@yahoo.com.br

\begin{abstract}
Resumo
Este artigo contemplou a crônica e a charge, por meio da linguagem verbal e visual exploradas na temática da "intimidade" na charge de Luiz Osvaldo Rodrigues (LOR), premiada em 4o lugar no Salão Internacional de Humor de Piracicaba em 1980 e publicada pela Imprensa Oficial na coletânea "Piracicaba 30 anos de Humor", por José Machado e Heitor Gaudenci Junior em 2003, e a crônica de Luis Fernando Veríssimo publicada em 1999 na coletânea "Historias Brasileiras de Verão" sob o título "Momento Propício" com um acentuado senso de humor explorado nestas linguagens.
\end{abstract}

Palavras Chave: Crônica; Charge; Humor.

\begin{abstract}
This article included the chronic and charge through the verbal and visual explored the theme of "intimacy"in charge of Osvaldo Luiz Rodrigues (LOR), premiered in fourth place at tha Internacional Humor Exhibition of Piracicaba in 1980 and published by the Press Office in the collection "30 years of Piracicaba humor", by José Machado and Heitor Gaudenci Junior in 2003, and Luis Fernando Verissimo chronic published in 1999 in the anthology "Stories Brazilian summer"under the "right moment" with a sharp sense of humor exploited in these languages.
\end{abstract}

Keywords: Chronic; Charge; Humor.

\section{Introdução}

Este artigo tem como base fundamental a pesquisa sobre charge e crônica, procurando compreender as diferenças e semelhanças produzidas pelas imagens e pelo texto, por meio da linguagem verbal e visual, que trabalham no mesmo campo com referências do cotidiano.

Observa-se um interesse nos últimos tempos pelo efêmero, pelo humor rápido, pelo reconhecimento nas imagens de si mesmo, pela agilidade na informação. Tendências da sociedade moderna (ou pós-moderna) que ri de si mesma, assim o humor consistiria no sentimento do contrário, provocado pela reflexão, que não se oculta nem se converte em forma de sentimento, mas em seu contrário, em sua negação, acompanhando o sentimento como uma sombra. Neste sentido o humor seria a reflexão que se exercita antes ou depois do fato cômico, conservando a possibilidade do contrário, mas eliminando o nosso distanciamento e a nossa superioridade.

O humor faz parte deste meio literal de transmissão de informações, relacionando-o 
Crônica e Charge: o Cotidiano e Suas Representações

enquanto crítica no universo visual gráfico e lingüístico, através da charge e da crônica, levando a informação ao leitor através de personagens que representem os indivíduos sociais e fazendo com que estes possam refletir de forma crítica sobre sua realidade. [...] "Graças ao que na imagem (e que na verdade, é muito pouca coisa) podemos passar sem as palavras e continuamos a nos entender" (BARTHES, 1990, p. 21).

Como insistia o sociólogo da literatura, Lucien Goldman (apud SAYRE; LOWY, 2001), a teoria formula os conceitos, as leis, as análises, e a obra literária ganha vida através dos indivíduos, dos personagens e das situações. Se a primeira segue a lógica da racionalidade científica, a segunda segue a da imaginação e, dessa forma, produz um "efeito de conhecimento" insubstituível, iluminando, por assim dizer, o "interior", os contornos e as formas da realidade social. O que implica uma complementaridade possível, e desejável, entre as duas formas de discurso.

Em relação à sociologia do personagem, a tipicidade não é um dado objetivo que o personagem deva adequar para tornar-se esteticamente (ou ideologicamente) válida, mas resulta da relação de fruição entre personagem e leitor. Enfim, é um reconhecimento (ou uma projeção) que o leitor realiza diante do personagem. Entende-se por "tipo" uma abstração ou conceito. Assim, a arte se torna substitutiva do pensamento filosófico. Ou ainda, pode-se considerar "[...] por típico o individual, também aqui se faz uma simples variação de palavras. Tipizar comportará, nesse caso, caracterizar, ou seja, determinar e representar o indivíduo" (ECO, 1970, p.212).

Refletindo a metáfora especular, Silva (1990) ratifica que o personagem reflete o existente na vida social, destacando a presença do imaginário como elemento na experiência dos grupos sociais para quem ele era significativo.

De acordo com a breve explanação acima citada, pretende-se, com este artigo, observar a temática da "intimidade" na charge de Luiz Osvaldo Rodrigues e na crônica de Luis Fernando Veríssimo, bem como o reflexo da temática nestas linguagens.

Para tanto, será analisada uma charge e uma crônica, pelas suas particularidades e semelhanças. A charge de Luiz Osvaldo Rodrigues (LOR), premiada em 4ㅇ lugar Salão Internacional de Humor de Piracicaba em 1980 e publicada pela Imprensa Oficial na coletânea Piracicaba 30 anos de humor, por José Machado e Heitor Gaudenci Junior em 2003, e a crônica de Luis Fernando Veríssimo publicada em 1999 na coletânea Histórias Brasileiras de Verão sob o título Momento Propício com um acentuado senso de humor, abordam um tema extremamente delicado e íntimo.

Sendo assim, espera-se levantar e discutir a temática "intimidade" instaurada na charge e na crônica, acima citadas, embasadas especialmente na teoria literária e sociológica, além da analise da imagem.

\section{Características da Charge e da Crônica}

As artes visuais refletem o exercício da interação com a imagem; a experiência da imagem, anterior à da palavra, vem enraizar-se no corpo. A imagem é afim à sensação visual. $O$ ser vivo tem, a partir do olho, as formas do sol, do mar, do céu. O perfil, a dimensão, a cor.

A imagem é um modo da presença que tende a suprir o contato direto e a manter, juntas, a realidade do objeto em si e a sua existência em nós. $O$ ato de ver apanha não só a aparência da coisa, mas alguma relação entre nós e essa aparência: primeiro e fatal intervalo (BOSI, 1974, p.65). 
São chamadas de artes gráficas todas as imagens que têm como fim comunicar através de elementos visuais uma dada mensagem para persuadir o observador ou leitor, guiar sua leitura ou transmitir uma idéia ou crítica. Talvez isso delimite de forma mais efetiva o campo das artes gráficas.

As formas pictóricas e caricaturais situadas nas artes gráficas ganham vida através do humor.

[...] De 'ligeiro' a 'inofensivo', passando pela irresponsabilidade, pela superficialidade e pela imoralidade, o humor tem sido freqüentemente desqualificado como forma de expressão social. Um dos argumentos reincidentes nesse discurso é a vinculação imediata e crua do humor com os fatos cotidianos. Daí as categorias de superficial, ligeiro e menor que the são atribuídas. É como se existisse um saber superior pairando sobre a realidade acidentada do cotidiano, capaz de ordenar os fatos, dando-Ihes lógica e sentido (VELLOSO, 1996, p.89).

A charge e a crônica, utilizadas como meio de expressão humorística são tomadas como inofensivas, isto é não causam danos, são propensas a provocar o riso hilariante.

Essa relação de tempo e memória pode ser indicada como um elo entre charge e crônica, pois nestas formas de linguagem verbal e visual esta é uma característica essencial, relacionada com a própria origem grega da palavra, Chronos, que significa tempo. Portanto, a crônica, desde sua origem, é um "relato em permanente relação com o tempo, de onde tira, como memória escrita, sua matéria principal, o que fica do vivido" (ARRIGUCCI JR, 1987).

Na crônica, "Tudo é vida, tudo é motivo de experiência e reflexão, ou simplesmente de divertimento, de esquecimento momentâneo de nós mesmos a troco do sonho ou da piada que nos transporta ao mundo da imaginação. Para voltarmos mais maduros à vida..." (CÂNDIDO, 1993, p.54).

Segundo Simon (2004, p.13), o cronista apresenta "vocação para o comentário, para a análise, para por determinados assuntos em discussão, para usar certas cenas como pontos de partida, motes para um debate literário".

No Brasil, a crônica se consolidou por volta de 1930 e atualmente vem adquirindo uma importância maior em nossa literatura graças aos excelentes escritores que resolveram se dedicar exclusivamente a ela, como Rubem Braga e Luís Fernando Veríssimo, além dos grandes autores brasileiros, como Machado de Assis, José de Alencar e Carlos Drummond de Andrade, que também resolveram dedicar seus talentos a esse gênero. Tudo isso fez com que a crônica se desenvolvesse no Brasil de forma extremamente significativa.

A crônica tem preocupação direta com o cotidiano, assim como a charge, o cronista tem compromisso com fatos cotidianos e usa-os como meio ou pretexto para exercer seu estilo e criatividade, além de geralmente usar de humor, leveza, lirismo, sensibilidade, síntese, narrativa informal, familiar e intimista.

\section{Temática "Intimidade" explorada na crônica e na charge}

A temática intimidade esta presente tanto na charge quanto na crônica. A palavra intimidade significa vida particular. Na língua latina o termo apresenta também o significado de temas ou assuntos íntimos, afeto, confiança, amor, sexualidade e família.

$\mathrm{Na}$ imagem escolhida para retratar a charge vemos um casal que se esforça e tenta várias peripécias para chegar ao clímax, e a mulher tenta várias posições em uma cadeira dobrandose cada vez mais e emitindo ruídos sonoros, o casal aparenta ser de meia idade, percebe-se e

Projética Revista Científica de Design I Universidade Estadual de Londrina I V.2 I N.1 I Junho 2011 
Crônica e Charge: o Cotidiano e Suas Representações

pela condição física de ambos, mas que ao final destes malabares e desta tentativa de prazer de forma não convencional eles acabam com câimbras, de quatro no chão, ao que parecia ser muito prazeroso acabe-se tornando doloroso.

Esta imagem ainda reflete o momento íntimo entre o casal, a noite pelo fundo preto da imagem, a necessidade de experimentar novas posições, e a insegurança da mulher, que tenta sair da zona de conforto mostrando ao seu parceiro que ela também pode agradá-lo.

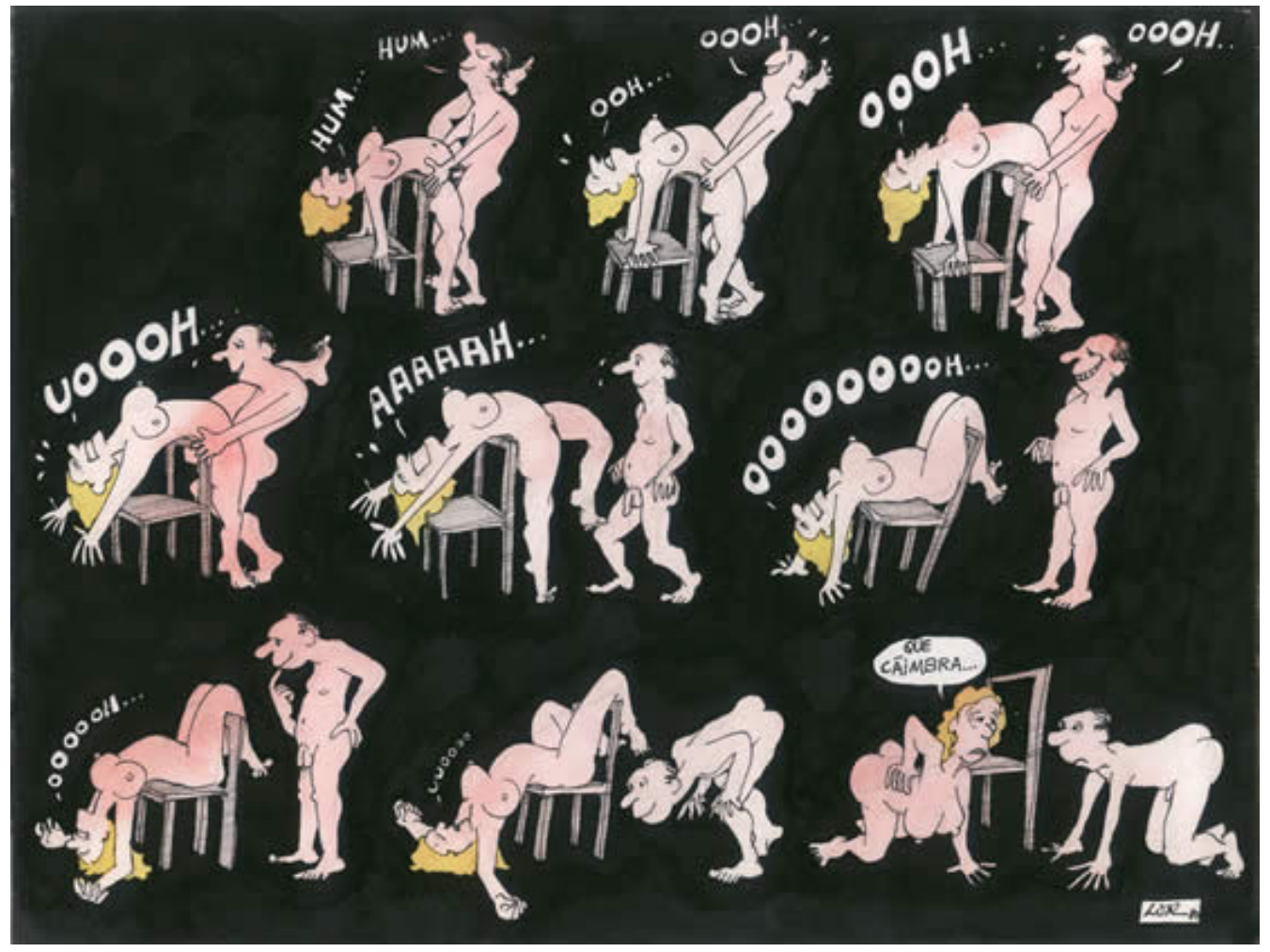

Figura 1- Charge de um casal

Fonte: Luiz Osvaldo Rodrigues (LOR), Piracicaba 30 anos de humor (2003, p. 85).

Levado a pesquisar este tema Guiddens (1993, p.79) pergunta: "as mulheres querem sexo?" E obtém a resposta que sim, "pela primeira vez as mulheres coletivamente, e não como especialistas em uma ars erótica, são capazes de buscar prazer sexual como um componente básico de suas vidas e de seus relacionamentos".

Ainda segundo Guiddens (1993), a vida social é substancialmente transformada em rotina: temos modos de atividade regulares, que repetimos dia após dia, e que dão forma às nossas vidas individuais, e o sexo enquadra-se também nesta rotina.

Sendo assim alguns casais buscam a satisfação sexual e chegam a sexualidade compulsiva, compreendida como pano de fundo das "circunstâncias em que a experiência sexual tem-se tornado mais livremente disponível do que jamais o foi, e em que a identidade sexual forma uma parte central da narrativa do eu" (GUIDDENS, 1993, p.90).

Já a crônica de Luis Fernando Veríssimo (1999, p.75) “Momento Propício" mostra a necessidade masculina e o desejo de possuir a mulher de forma inusitada, enquanto se encontram sozinhos em casa, ela entre seus afazeres domésticos e ele tomado de desejo repentino, tenta convencêla de que o sexo em locais inesperados para tal seria mais atraente.

O esposo chega em casa mais cedo e encontra a esposa sozinha, e tem o desejo de possuí-la na cozinha, onde ela esta a guardar as compras que trouxera do supermercado, então ele tenta convencê-la da mesa, depois no chão, na mesa da sala de jantar, na sala, no sofá, no 
chão da sala, ela não consentiu e protestou: no quarto! Mas ele não achava que quarto era lugar para aquilo, e pensa: "Há muito tempo que é tarde [...]. E, mesmo assim aquela agitação não fizera nada bem para sua coluna. Gritou para a cozinha: Quando vier daí traz as minhas calças" (VERÍSSIMO, 1999, p.78) .

A caça para a conquista sexual produz o mesmo ciclo destruidor de desespero e desilusão observado em outros vícios, segundo Guiddens (1993, p.92) o êxtase do orgasmo é um momento de triunfo e também de liberação física e emocional; "mas muitas experimentam um êxtase também ao se prepararem para um encontro sexual, quando se sentem particularmente despertas e até eufóricas".

Assim sendo o personagem da crônica, o marido frustrado, sente-se destruído e desiludido, com a incompreensão da esposa, que o repele, que não atende aos seus instintos e desejos, preocupando-se mais com os afazeres domésticos, com a casa, percebe-se ainda o quanto o homem nesta crônica é viril e tomado de desejo.

\section{Considerações Finais}

Tendo em vista a discussão empreendida nesse artigo, nota-se entre a charge e a crônica um elo unindo estes meios de comunicação, pois a intimidade revelada na linguagem visual e verbal revela que um explica e até complementa o outro.

Por meio da crônica e da charge, tem-se a idéia de que as coisas não tem uma forma única, mas se apresentam de distintas maneiras, dependendo do olhar do observador, completando a "cultura da modernidade".

É através do humor, de pequenas cenas narradas, reais ou não, e de muitos comentários que eles contribuem para as reflexões do leitor e para um destino mais consciente de que homens e mulheres darão a seus corpos, sem que eles percam a noção dos valores que fundamentam o mundo sexualizado contemporâneo (SIMON, 2004, p.20).

Neste sentido, segundo Saliba (2002, p.25) o humorismo seria a reflexão que se exercita antes ou depois do fato cômico, conservando a possibilidade do contrário mas eliminando o nosso distanciamento e a nossa superioridade.

Neste confronto entre imagem e texto temos dois casais que terminam infelizes, o primeiro da charge por ter tentando inovar o sexo com varias posições, tentando fugir da mesmice, enquanto o casal da crônica não consegue chegar ao clímax pois a mulher não aceita estas inovações que o homem propõe.

"Atualmente, para ambos os sexos, o sexo carrega com ele a promessa - ou a ameaça - da intimidade, algo que em si afeta os principais aspectos do eu" (GUIDDENS, 1993, p.91). Em meio a estas exposições carnais, sensuais, carregadas de apelo sexual podemos nos questionar de quanto à intimidade mesmo que em quatro paredes é violada e explorada, ameaçando como afirma Guiddens (1993) este espaço íntimo.

\section{Referências}

ARRIGUCCI JR, Davi.Fragmentos sobre a crônica. Folha de São Paulo, São Paulo, 1 maio 1987.

BARTHES, R. O óbvio e o obtuso. Rio de Janeiro: Nova Fronteira, 1990. 
Crônica e Charge: o Cotidiano e Suas Representações

BOSI, Alfredo. Imagem, Discurso. Revista Discurso, São Paulo, n. 5, 1974.

CANDIDO, A. Recortes. São Paulo: Companhia das Letras, 1993.

ECO, Umberto. Apocalípticos e Integrados. São Paulo: Perspectiva, 1970.

GUIDDENS, A. A transformação da intimidade: sexualidade, amor e erotismo, nas sociedades modernas. São Paulo: Ed. UNESP, 1993.

MACHADO, José; GAUDENCI J. Heitor. Piracicaba 30 anos de humor. São Paulo: Imprensa Oficial do Estado: Instituto do Memorial de Artes Gráficas do Brasil, 2003.

SALIBA, E. T. Raízes do Riso: e a representação humorística na história brasileira: da Belle Époque aos primeiros tempos do rádio. São Paulo: Cia das Letras, 2002.

SAYRE, R.; LOWY, M. Reificação e Consumismo Ostentório no Gatsby O Magnífico.

Estudos de Sociologia, Araraquara, ano 6, n. 11, 2001.

SILVA, Marco Antonio. Caricata República. São Paulo: Marco Zero, 1990.

SIMON, Luiz Carlos Santos. Corpo e sexualidade na crônica contemporânea. Boletim - Revista da Área de Humanas. Londrina, n..47, p.9-20, 2004.

VELLOSO, M. P. Modernismo no Rio de Janeiro: turunas e quixotes. Rio de Janeiro: Fundação Getúlio Vargas, 1996.

VERISSIMO, Luis Fernando. Historias Brasileiras de Verão. Rio de Janeiro: Ed. Objetiva, 1999. 